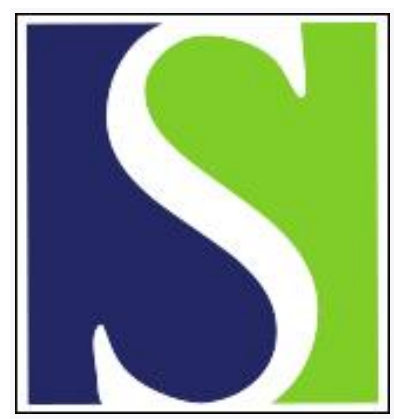

Scand J Work Environ Health 2004;30(2):149-156

https://doi.org/10.5271/sjweh.772

Issue date: Apr 2004

Direction of shift rotation among three-shift workers in relation to psychological health and work-family conflict

by van Amelsvoort LGPM, Jansen NWH, Swaen GMH, van den Brandt PA, Kant I

Affiliation: Department of Epidemiology, Maastricth University, PO Box 616, 6200 MD Maastricht, The Netherlands. Igpm.vanamelsvoort@epid.unimaas.nl

Refers to the following texts of the Journal: $1999 ; 25(2): 85-99$ 1999;25(3):272-277 1999;25(2):100-104 2002;28(1):64-71 1998;24 suppl 3:3-6

The following articles refer to this text: 2006;32(6):502-514; 2007;33(1):51-57; 2008;34(3):206-212; SJWEH Supplements 2008;(5):14-21; 2010;36(2):96-108; 2010;36(2):121-133; 2011;37(5):402-410; 2011;37(6):551-555; 2015;41(4):356-367; $2018 ; 44(1): 69-79 ; 2019 ; 45(3): 256-266$

Key terms: cohort study; health; psychological health; shift rotation; shift work; shift worker; three-shift worker; work schedule; work-family conflict

This article in PubMed: www.ncbi.nlm.nih.gov/pubmed/15143742

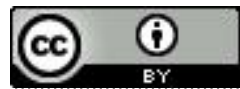




\title{
Direction of shift rotation among three-shift workers in relation to psychological health and work-family conflict
}

\author{
by Ludovic GPM van Amelsvoort, PhD, ${ }^{1}$ Nicole WH Jansen, PhD, ${ }^{1}$ Gerard MH Swaen, PhD, ${ }^{1}$ Piet $A$ van \\ den Brandt, PhD, ${ }^{1}$ IJmert Kant, $P h D^{1}$
}

\begin{abstract}
van Amelsvoort LGPM, Jansen NWH, Swaen GMH, van den Brandt PA, Kant I. Direction of shift rotation among three-shift workers in relation to psychological health and work-family conflict. Scand J Work Environ Health 2004;30(2):149-156.
\end{abstract}

\begin{abstract}
Objectives The aim of the present study was to investigate whether the direction of shift rotation was related to the need for recovery, fatigue, sleep quality, work-family conflict, and leisure time among three-shift workers. Methods Data of 95 workers in forward-rotating three-shift work and 681 workers in backward-rotating threeshift work, with 32 months of follow-up, in the Maastricht cohort study ( $\mathrm{N}=12$ 095) were used. Both crosssectional and longitudinal analyses were carried out.

Results A backward rotation schedule was prospectively related to an increased need for recovery [relative risk (RR) 2.88, 95\% confidence interval (95\% CI) 1.06-7.81] and poor general health (RR 3.21, 95\% CI 1.32-7.83), as compared with a forward rotation schedule. Adjustment for demographic and health variables and the characteristics of the work environment did not alter these relations considerably. Furthermore, a forward rotation schedule was prospectively related to less work-family conflict and better sleep quality over the 32 months of follow-up. Finally, high levels of fatigue, need for recovery, poor sleep quality, poor general health, insufficient leisure time, and work-family conflict at first measurement were associated with an increased risk of leaving shiftwork during the follow-up.

Conclusions Optimization of shiftwork schedules, in terms of shift rotation, seems a promising method for decreasing the negative impact accompanying shiftwork. Future studies should investigate whether these findings for three-shift workers are applicable to other shiftwork schedules as well. Furthermore, this study clearly illustrates the existence of secondary selection processes among shiftworkers and thereby emphasizes the complexity of valid shiftwork research.
\end{abstract}

Key terms cohort study, shiftwork, work schedule.

A considerable and still increasing part of the working population works outside normal workhours. Within the European Union, $19 \%$ of the workforce, or well over 31 million persons, work at least one night per month $(1,2)$. Most of these people work in shifts. Generally, shiftwork can be defined as work that includes working outside normal workhours. Most shiftwork includes nightwork. Many different shiftwork schedules can be distinguished. Shiftwork schedules can roughly be divided into discontinuous (two-shift), semi-continuous (three-shift), continuous (four-, five- and six-shift), and irregular work schedules. Shift- and nightwork have been associated with considerable negative impacts on health and well-being. Effects have been reported for cardiovascular $(3-7)$ and gastrointestinal $(8,9)$ health, obesity $(10,11)$, the metabolic syndrome (12), sleepiness (13), need for recovery from work (14), fatigue (15-19), accidents (8), and well-being (20).

To decrease the potential adverse health effects of shiftwork, the application of healthier shift systems has been suggested $(16,21-23)$. One of the possibilities within three-, four-, five-, or six-shift work is the choice for forward or backward rotation of shift schedules. Several studies have reported on different health effects of a forward versus a backward rotation shift schedule. A shift system that first moves from a morning shift to an evening shift and then to a night shift has a forward rotation (also called phase delay or clockwise rotation). Counterclockwise rotation (night to evening to morning) is called backward rotation or phase advance (24).

1 Department of Epidemiology, Maastricht University, The Netherlands.

Reprint requests to: Dr Ir Ludovic van Amelsvoort, Department of Epidemiology, Maastricht University, PO Box 616, 6200 MD Maastricht, The Netherlands. [E-mail: lgpm.vanamelsvoort@epid.unimaas.nl] 
As early as 1982, Czeisler et al (21) reported that, by changing from backward to forward rotation, the health index score of the workers increased favorably. Compared with forward rotation shift systems, backward rotation systems have further been associated with poorer physical and psychological health, including chronic fatigue (16), more unfavorable cardiac autonomic control (25), adverse changes in self-rated health, duration and quality of sleep, and unhealthy systolic blood pressure, serum glucose, uric acid and triglyceride levels (26). Following shiftworkers who changed from a backward to a forward rotation system, and from slow to rapid rotation, Knauth \& Kiesswetter (27) reported a reduction in sleep difficulties in association with nightshifts. Three related factors favor forward rotation over backward rotation (28). First, the cyclic period of the endogenous circadian rhythm runs slightly longer than 24 hours if allowed to free-run, or oscillate, without respect to external time cues. Second, with respect to the clock, it is easier to delay sleep onset through voluntary activity than to advance it. Third, forward rotation schedules often allow more than 24 hours of free time before rotating to the new shift, and, therefore, they provide more opportunities for rest and sleep.

Although fatigue and the need for recovery from work can be regarded as important indicators of the adverse (psychological) health effects of shiftwork (14, 18), they have not been extensively investigated. Prolonged fatigue affects a worker's performance in both the work and home setting. It is related to increased accident risk (29) and may lead to sick leave and work disability (30). Rosa (28) suggested that backward rotation schedules could produce more fatigue than those rotating in a forward direction. Only two studies on fatigue $(16,31)$, and no studies on need for recovery from work, and the direction of shift rotation have been found. The intervention study by Barton et al (32), in which a group of 120 workers who changed from a forward to a backward rotation schedule was studied, showed little change during the intervention. Only the number of sleep difficulties increased during the backward rotation, but the reported social disruption decreased. Tucker et al (31) reported results from a cross-sectional comparison between forward and backward rotation. They found a small, favorable effect of backward rotation on sleep duration but no effect on alertness or chronic fatigue.

A frequently mentioned argument of shiftworkers against a change in shift schedule from backward to forward rotation is the apparent decrease in leisure time and possible increase in conflict between work and family life. Work-family conflict among shiftworkers is often thought to arise because shiftwork involves working and living patterns that diverge from community rhythms of social, recreational, and domestic activity $(33,34)$. Unfortunately, surprisingly few studies on these outcomes have been conducted. In an earlier study, we found that shiftworkers reported a higher risk of work-family conflict when compared with dayworkers (35). Work-family conflict is a perception of insufficient energy and time to combine work and family roles successfully (36). Backward and forward rotation systems result in a different pattern of leisure time between consecutive shifts. In this respect the direction of rotation may be related to work-family conflict as well.

Improvements in the design of shift schedules could help to reduce the negative effects accompanying shiftwork and therefore help prevent employees from leaving shiftwork.

If the direction of rotation proves to be related to the need for recovery, fatigue, and work-family conflict among shiftworkers, then companies would have a clear utilizable tool with which to reduce fatigue-related outcomes and work-family conflict among shiftworkers. The aim of our present study was to investigate whether the direction of rotation in three-shift work was related to the need for recovery, fatigue, sleep quality, work-family conflict, and leisure time. Furthermore, we investigated whether these (health) outcomes were prospectively related to leaving shiftwork over time. We used data from the Maastricht cohort study on fatigue at work to assess the aims both in a cross-sectional and longitudinal design.

\section{Participants and methods}

\section{Study population}

For the current study, data from the Maastricht cohort study on fatigue at work were used. This study has been described in detail elsewhere $(37,38)$. In short, this prospective study was established in May 1998 and had a baseline response rate of 45\%. Altogether 12140 workers, employed by 45 different companies, mostly located in the southern part of The Netherlands, were followed for 32 months. For the present study, the exclusion criteria were (i) being absent from work at the time the baseline questionnaire was completed and (ii) not having completely resumed work after a period of sick leave at the time of the baseline survey. Also excluded were employees with multiple jobs, since we had no information on worktime arrangements or the content of additional jobs.

Because of the small numbers in the other shift schedule groups and the low number of female shiftworkers in the cohort, this study focused on male threeshift workers only. Five-shift workers were excluded because of the incomparability between workers in forward and backward rotation schedules with regard to job 
title and socioeconomic status. This exclusion resulted in a final study population at baseline of 776 three-shift workers, capturing 95 workers in forward rotation and 681 workers in backward rotation. To study the prospective relationship between direction of rotation and the outcomes, we used the data available after 32 months of follow-up. The response rates at the eight consecutive time points have been described elsewhere $(18,38)$. For the longitudinal analyses, employees who received a retirement pension or stopped work in a three-shift schedule job were no longer considered to be at risk of becoming a case and were therefore excluded from the analysis. Because contrasting results were observed between the cross-sectional and longitudinal analyses, additional analyses were carried out to assess whether the baseline levels of the main outcome variables were related to a higher risk of leaving shiftwork. Also for these analyses, persons leaving shiftwork due to early retirement were excluded.

As shown in table 1, forward-rotating three-shift workers were slightly older, averaged more years of three-shift work experience, and were somewhat more highly educated than the backward-rotating three-shift workers. No substantial differences were observed between the forward- and backward-rotating three-shift workers with regard to work-related factors, such as psychological job demands, decision latitude, physical demands, social support from co-workers and supervisors, and flexible workhours at baseline. However, the forward-rotating workers reported less overtime work. The backward-rotating workers reported more fatigue and work-family conflict and were less often living with a partner at baseline, although the difference between the backward rotating and forward-rotating workers was not significant. For the other factors only small differences were found between the two groups, the differences being a little less favorable for the forward-rotating workers.

\section{Measures}

Work schedules. The baseline questionnaire included 32 questions on worktime arrangements that enabled us to describe the work schedules of the employees in detail. Information on direction of shift rotation was gathered through the company records on work schedules. In our study, three-shift work, also referred to as $3 \times 8$ semi-continuous shiftwork, involved continuous 24-hour production from Monday through Friday carried out by three teams of employees, generally working 8-hour shifts. As a rule, in three-shift work, teams are switched every week. Therefore, the teams work five morning, evening, or night shifts in a row. The precise start and end times of the different shifts differed for the participating companies. However, as a rule, in The Netherlands the start of a morning shift is between 0600 and 0800 , evening shifts begin between 1400 and 1600, and nightshifts commence between 2200 and 2400. Three-shift work generally comprises 36 to 40 workhours a week. The majority of three-shift workers in our study were employed in the paper and automobile industry.

Need for recovery from work. The need for recovery was assessed using an 11-item subscale of the VBBA (Dutch Questionnaire on Experience and Assessment of Work) (39-41) with questions like "I find it hard to relax at the end of a workday" and "When I get home, people should leave me alone for some time". An average score was calculated ranging from 0 to 100 . The need for recovery from work was measured every 4 months. There was no existing cut-off point for the scale to classify "cases" with very high scores on the scale. Therefore, in our study, the upper quartile of the score of the entire cohort study was used to define a contrast between employees with considerable need for recovery from work (upper quartile) versus employees with a lower need for recovery from work (lowest three quartiles).

Table 1. Baseline characteristics of the forward- and backwardrotating male three-shift workers.

\begin{tabular}{|c|c|c|c|c|c|c|c|}
\hline \multirow[t]{2}{*}{ Variable } & \multicolumn{3}{|c|}{$\begin{array}{c}\text { Forward } \\
(\mathrm{N}=95)\end{array}$} & \multicolumn{3}{|c|}{$\begin{array}{l}\text { Backward } \\
(\mathrm{N}=681)\end{array}$} & \multirow{2}{*}{$\begin{array}{c}\text { P- } \\
\text { value } \\
\text { differ- } \\
\text { ence }\end{array}$} \\
\hline & Mean & SD & $\%$ & Mean & SD & $\%$ & \\
\hline \multicolumn{8}{|l|}{ Demographics } \\
\hline Age (years) & 40.9 & 8.8 & . & 36.4 & 8.3 & . & $<0.0001$ \\
\hline \multicolumn{8}{|l|}{ Educational level } \\
\hline Lower & . & & 79.4 & . & . & 65.3 & 0.02 \\
\hline Secondary & . & & 17.4 & . & . & 31.0 & . \\
\hline Higher & . & $\cdot$ & 3.3 & . & . & 3.8 & .. \\
\hline \multicolumn{8}{|l|}{$\begin{array}{l}\text { Years of work experience } \\
\text { in same shift }\end{array}$} \\
\hline$\leq 5$ years & . & & 44.7 & . & . & 78.5 & $<0.0001$ \\
\hline $6-15$ years & . & & 17.0 & . & . & 11.0 & . \\
\hline$>15$ years & & & 38.3 & . & . & 11.5 & . \\
\hline \multicolumn{8}{|l|}{ Work conditions } \\
\hline \multicolumn{8}{|l|}{ Psychological job } \\
\hline Decision latitude & 65.7 & 12.8 & . & 65.1 & 13.8 & . & 0.7 \\
\hline \multicolumn{8}{|l|}{ Social support } \\
\hline Co-workers & 11.8 & 2.0 & . & 11.8 & 1.8 & . & 0.9 \\
\hline Supervisors & 9.1 & 2.7 & . & 9.7 & 2.8 & . & 0.05 \\
\hline Physically demanding work & . & & 52.2 & . & . & 47.5 & 0.4 \\
\hline Overtime work & . & & 25.5 & . & . & 41.3 & 0.004 \\
\hline Flexible work hours & . & . & 3.2 & . & . & 2.8 & 0.8 \\
\hline \multicolumn{8}{|l|}{ Work-home interaction } \\
\hline Dependent children & . & & 50.5 & . & . & 50.7 & 0.99 \\
\hline Living with partner & . & & 83.9 & . & . & 75.0 & 0.06 \\
\hline Insufficient leisure time & . & & 38.0 & . & . & 37.3 & 0.9 \\
\hline Work-family conflict & . & & 25.6 & . & . & 34.4 & 0.09 \\
\hline \multicolumn{8}{|l|}{ Psychological health } \\
\hline Fatigue cases & . & & 22.0 & . & . & 29.6 & 0.13 \\
\hline Considerable need for recov & very. & & 38.0 & . & . & 36.0 & 0.7 \\
\hline Poor sleep quality & . & & 36.6 & . & . & 30.5 & 0.3 \\
\hline Poor general health & . & & 19.4 & . & . & 17.2 & 0.6 \\
\hline
\end{tabular}


Fatigue. In our study, fatigue was considered a subjective sensation with cognitive and behavioral components. Furthermore, we only dealt with fatigue persistent over a period of several days, also called prolonged fatigue. Fatigue was measured with the 20-item, selfreported Checklist Individual Strength (CIS), which has been described extensively elsewhere $(42,43)$. A composite CIS total score, ranging from 20 to 140, was calculated by adding all the individual scores. For the classification of the fatigue cases, the cutoff point of the CIS (total >76) was used (43). Fatigue was measured every 4 months.

Sleep quality. Sleep quality was assessed using the following self-formulated question: "Did you sleep well during the last four months?" with the precoded answer categories of "never", "sometimes", "mostly", and "always". We defined sleep quality as poor for the respondents reporting "never" or "sometimes". This item was queried every 4 months.

General health status. Self-rated general health was inventoried by one item, adapted from the SF-36 Health Survey, which is a widely used generic health status measure (44). This item was scored on a 5-point scale and measured every 4 months. General health was defined as poor if the response was "moderate" or "bad".

Work-home interaction. To measure work-family conflict, the following item was used: "Are you able to adequately combine work and family life?" Furthermore, employees were asked if they felt they had sufficient leisure time, besides work and family life. The response to these self-formulated items was "yes" or "no". These items were measured once a year.

\section{Confounding factors}

Demographics and health factors. Data on age, gender, educational level, care of dependent children, living with a partner, and presence of a long-term disease were collected at baseline.

Work-related factors. Overtime work, flexible workhours, and years of work experience in the current shift schedule were assessed through self-reports in the questionnaire. Psychological demands and decision latitude were assessed using the Dutch version of the self-administered Job Content Questionnaire (JCQ) (45, 46). Social support was assessed by two scales of the JCQ (supervisors' support and co-workers' support) each consisting of four items. The response options varied from "strongly disagree" to "strongly agree" on a fourpoint scale. To assess whether employees perceived their work as physically demanding, we used one item of the Dutch questionnaire on work and health (VAG) (47).

\section{Statistical analysis}

Independent sample t-tests and chi-square tests were used to test the univariate differences between the groups of employees with a different direction of rotation. Multivariate survival analyses using Cox regression were performed in three steps to examine prospectively the role of direction of shift rotation, measured at the baseline in $1998\left(\mathrm{~T}_{0}\right)$, in the onset of the different outcomes over time. For the need for recovery from work, fatigue, sleep quality, and general health status, we modeled the time to first "caseness" at $\mathrm{T}_{1}, \mathrm{~T}_{2}, \mathrm{~T}_{3}$, $\mathrm{T}_{4}, \mathrm{~T}_{5}, \mathrm{~T}_{6}, \mathrm{~T}_{7}$ or $\mathrm{T}_{8}$. Because work-family conflict and leisure time were asked about once a year, for these analyses, we modeled the time at $\mathrm{T}_{3}$, and $\mathrm{T}_{6}$ only. In these analyses, all prevalent cases from the involved dependent variable at baseline $\left(\mathrm{T}_{0}\right)$ were excluded. In a first step, crude relative risks (RR) and 95\% confidence intervals $(95 \% \mathrm{CI})$ were calculated. In a second step, adjustments were made for age, educational level, and the presence of a long-term disease. We adjusted the relative risks for years of shiftwork experience, psychological job demands, decision latitude, the social support of co-workers and supervisors, physical demands, and overtime work in a third step. In the two analyses, in which no incident cases occurred in one of the two groups, the relative risk was calculated by replacing the zero cases with one case and calculating a Taylor series $95 \%$ confidence interval. In these two instances no further adjustment could be performed. For the estimation of the relative risk of leaving a three-shift schedule, separate Cox regression models were evaluated with the baseline level of the psychological health, work and home variables as independents, with adjustment for age. For these analyses, we excluded the respondents who left their shiftwork job on retirement. Those who changed to day work or stopped working were designated as cases. All data were analyzed using SAS (48).

\section{Results}

As shown in table 2, a backward rotation schedule was prospectively related to increased need for recovery (RR 2.88, 95\% CI 1.06-7.81) and general health (RR 3.21, 95\% CI 1.32-7.83) during the total observation period of 32 months, as compared with a forward rotation three-shift system. Adjustment for age, educational level, years of shiftwork experience, presence of a longterm disease, psychological job demands, decision latitude, social support of co-workers and supervisors, 
Table 2. Relative risk (RR) for the psychological health outcomes and work-home interaction for the backward-versus forward-rotating three-shift workers during the 32 months of follow-up. (95\% Cl = 95\% confidence interval)

\begin{tabular}{|c|c|c|c|c|c|c|c|c|}
\hline Variable & $\begin{array}{l}\text { Incident } \\
\text { cases }\end{array}$ & $\mathrm{Na}^{\mathrm{a}}$ & $\mathrm{RR}$ & $95 \% \mathrm{Cl}$ & Adjusted RR ${ }^{a}$ & $95 \% \mathrm{Cl}^{\mathrm{b}}$ & Adjusted RR ${ }^{c}$ & $95 \% \mathrm{Cl}^{\mathrm{c}}$ \\
\hline \multicolumn{9}{|l|}{ Psychological health outcomes } \\
\hline Fatigue case & 124 & 532 & 1.90 & $0.89-4.09$ & 1.94 & $0.90-4.19$ & 1.36 & $0.61-3.06$ \\
\hline Considerable need for recovery & 112 & 485 & 2.88 & $1.06-7.81$ & 3.08 & $1.13-8.43$ & 2.99 & $1.06-8.44$ \\
\hline Poor sleep quality & 72 & 506 & $>7.36^{d}$ & $1.05-52.7$ & ..e & $\cdot \cdot$ & .. e & .. \\
\hline Poor general health & 164 & 623 & 3.21 & $1.32-7.83$ & 3.39 & $1.38-8.29$ & 2.77 & $1.10-7.00$ \\
\hline \multicolumn{9}{|l|}{ Work-home interaction } \\
\hline Insufficient leisure time & 40 & 468 & 2.32 & $0.56-9.63$ & 2.23 & $0.54-9.30$ & 1.86 & $0.43-8.08$ \\
\hline Work-family conflict & 64 & 493 & $>8.94 \mathrm{~d}$ & $1.26-63.4$ & ..e &.. &.. $\mathrm{e}$ &.. \\
\hline
\end{tabular}

a Number of respondents at risk at baseline.

${ }^{\mathrm{b}}$ Adjusted for age, educational level, and presence of a long-term disease.

${ }^{c}$ Adjusted for age, educational level, years of shiftwork experience, presence of a long-term disease, psychological job demands, decision latitude,

social support of co-workers and supervisors and physical demands and overtime work.

d No cases in forward-rotating group.

e Adjustment technically impossible due to empty cells.

physical demands, and overtime work did not alter this relation considerably. Furthermore, a backward rotation three-shift system at baseline was associated with a substantially higher risk of work-family conflict (RR $>8.94$, 95\% CI 1.26-63.4) and poorer sleep quality ( $R R>7.36$, 95\% CI 1.05-52.7) during the total observation period. Workers with a backward rotation schedule also reported more problems with insufficient leisure time over the total observation period, although this difference was not significant.

The results of the cross-sectional and longitudinal analyses yielded considerable differences concerning the health outcomes. Therefore, additional analyses, adjusted for age, were performed to explore the possibility that three-shift workers experiencing health problems were more likely to leave their shiftwork job over time (table 3 ). These analyses revealed that high levels of fatigue, need for recovery and poor sleep quality, reported poor general health status, insufficient leisure time, and work-family conflict were associated with an increased risk of leaving a shift job over the total observation period of 32 months.

\section{Discussion}

Our study examined the associations between the direction of shift rotation and several (psychological) health-related outcomes and work-home interaction among male three-shift workers. The cross-sectional analyses revealed few differences between three-shift workers in forward and backward rotation shift schedules. In the longitudinal analyses, however, we found that a forward rotation schedule was prospectively related to fewer psychological health-related problems, in terms of need for recovery, sleep quality, and general health, as compared with a backward rotation schedule. Furthermore, employees with a forward rotation
Table 3. Age-adjusted relative risk $(\mathrm{RR})$ for leaving $(\mathrm{N}=242)$ versus remaining in three-shift work $(\mathrm{N}=776)$ during 32 months of follow-up, according to baseline levels of the main outcome variables. $(95 \% \mathrm{Cl}=95 \%$ confidence interval)

\begin{tabular}{lcc}
\hline Variable & $\mathrm{RR}$ & $95 \% \mathrm{Cl}$ \\
\hline Fatigue case $(\mathrm{N}=214)$ & 1.76 & $1.36-2.29$ \\
Considerable need for recovery $(\mathrm{N}=275)$ & 1.60 & $1.23-2.07$ \\
Poor sleep quality $(\mathrm{N}=229)$ & 1.50 & $1.14-1.96$ \\
Poor general health $(\mathrm{N}=132)$ & 1.79 & $1.32-2.44$ \\
Insufficient leisure time $(\mathrm{N}=279)$ & 1.41 & $1.09-1.84$ \\
Work-family conflict $(\mathrm{N}=249)$ & 1.46 & $1.12-1.91$ \\
\hline
\end{tabular}

schedule were less likely to report work-family conflict than those with a backward rotation schedule.

Our findings of less favorable health outcomes among workers on a backward rotation schedule agree with the results of earlier studies regarding health outcomes and direction of rotation $(16,21-23)$. In line with the arguments favoring forward rotation, as reported by Rosa (28) and stated in the introduction section, we also argue that forward rotation schedules, as opposed to backward rotation schedules, are healthier for shiftworkers because they allow more time off between two blocks of similar shifts and therefore provide employees with more opportunities to recover from their shift and perhaps prevent further accumulation of fatigue. For the forward rotation schedules there is 16 hours more time to recover during the weekend than there is on the backward rotation schedules. However, at the end of every complete cycle of shifts, the workers in a backward rotation schedule have an extra day off.

Backward rotation schedules provide employees with a longer span of free time at the end of a complete shift cycle, but allow for less time for rest and sleep between two consecutive blocks of shifts than forward rotation shift schedules do. Nevertheless, a considerable part of the working population continues to work in backward rotation schedules. An important argument 
often encountered by shiftworkers is that a backward rotation schedule gives longer coherent periods of time off than a forward rotation schedule, where the free time "disappears" during the regular workday (49). Therefore, one might perhaps expect employees in a forward rotation schedule to report more work-family conflict. In contrast, however, we found that the forward-rotating workers reported less work-family conflict. Apparently, the "disappearing" time between consecutive shifts might be valuable for fine-tuning work and family obligations.

The results differed between the cross-sectional and longitudinal analyses. This difference may have been due to the "healthy worker effect", that is, due to secondary self-selection, shiftworkers experiencing shiftwork-related problems being more likely to leave shiftwork. This selection may be related to the years of shiftwork experience. However, adjustment for years of shiftwork experience did not change the reported relationships considerably. To explore whether such a selection process was present in our population, we performed an additional analysis examining whether the investigated outcomes, such as fatigue and work-family conflict, proved to be risk factors for leaving threeshift work. These analyses revealed that the respondents experiencing psychological health problems or workfamily conflict had a higher risk of leaving their shiftwork job. As far as we know, our study is the first to find such a clear illustration of these self-selection processes among shiftworkers. Unfortunately, the small number of employees did not permit a study of the risk factors involved in leaving three-shift work for backward- and forward-rotating shiftworkers separately. It is expected that the employees in a backward rotation schedule, associated with more health problems over time, would have a higher risk of leaving shiftwork when they encounter (psychological) health problems. On the other hand, forward-rotating shiftworkers encountering psychological health problems might already have left their shiftwork job, before our first measurement.

The following issues should be kept in mind when the results of our study are interpreted. First, one of the main problems in shiftwork research is finding appropriate comparison groups with comparable types of jobs. Although we only included workers from companies with comparable job types, one cannot rule out that differences between jobs may have biased the results. However, as the work conditions, as reported by the workers, did not significantly differ, one should assume that this bias is only small. Furthermore, different changes in job content over time between the workers in forward and backward shifts might have biased the results. However, additional analyses revealed no notable differences between these two groups in the trends of job content over time at three consecutive time points in May 1998, May 1999 and May 2000 (specific analyses not shown). The very small influence of additional adjustment for work-related factors provides additional support for this assumption. Second, as considerable differences exist between three-shift work schedules and other shiftwork schedules, such as four- and five-shift schedules, we consider an extrapolation of the results of the study to workers in other schedules to be inappropriate. The same goes for women. In our study the number of female workers in shiftwork jobs was not sufficient for us to estimate the effects of rotation for this subgroup. Nevertheless, our results favoring forward rotation do match the findings of studies on health effects and the direction of rotation in other shiftwork schedules.

To conclude, our study provides additional evidence that optimization of the shift schedule, in terms of direction of shift rotation, might be used to decrease the adverse health impact of shiftwork. Future studies could investigate whether our findings for three-shift workers are applicable to other shiftwork schedules as well. Although one should keep in mind that working in shifts remains unhealthy and should therefore be prevented whenever possible, from a health point of view, forward rotation is preferable over backward rotation in shift schedules when daywork is not feasible. Furthermore, this study provided a clear illustration of the secondary selection processes taking place among shiftworkers and, thereby, emphasizes the complexity of valid shiftwork research.

\section{Acknowledgments}

The Maastricht cohort study is part of the concerted research action on "fatigue at work" funded by The Netherlands Organization for Scientific Research. Our present study was supported by grant 580-02.201 from The Netherlands Organization for Scientific Research.

\section{References}

1. European Commission. Employment in Europe 2001-recent trends and prospects. Luxembourg: Office for Official Publications of the European Communities; 2001.

2. European Foundation for the Improvement of Living and Working Conditions. Third European survey on working conditions 2000. Luxembourg: Office for Official Publications for the European Communities; 2001.

3. Bøggild H, Knutsson A. Shift work, risk factors and cardiovascular disease [review]. Scand J Work Environ Health 1999;25(2):85-99. 
4. Knutsson A, Bøggild H. Shiftwork and cardiovascular disease: review of disease mechanisms. Rev Environ Health 2000;15(4):359-72.

5. Murata K, Yano E, Shinozaki T. Impact of shift work on cardiovascular functions in a 10-year follow-up study. Scand J Work Environ Health 1999;25(3):272-7.

6. Morikawa Y, Nakagawa H, Miura K, Ishizaki M, Tabata M, Nishijo M, et al. Relationship between shift work and onset of hypertension in a cohort of manual workers. Scand J Work Environ Health 1999;25(2):100-4.

7. Van Amelsvoort LG, Schouten EG, Maan AC, Swenne CA, Kok FJ. Changes in frequency of premature complexes and heart rate variability related to shift work. Occup Environ Med 2001;58(10):678-81.

8. Angersbach D, Knauth P, Loskant H, Karvonen MJ, Undeutsch K, Rutenfranz J. A retrospective cohort study comparing complaints and diseases in day and shift workers. Int Arch Occup Environ Health 1980;45:127-40.

9. Tüchsen F, Jeppesen HJ, Bach E. Employment status, nondaytime work and gastric ulcer in men. Int J Epidemiol 1994; 23:365-70.

10. Parkes KR. Shift work and age as interactive predictors of body mass index among offshore workers. Scand J Work Environ Health 2002;28(1):64-71.

11. Van Amelsvoort LGPM, Schouten EG, Kok FJ. Duration of shiftwork related to body mass index and waist to hip ratio. Int J Obesity 1999;23(9):973-8.

12. Karlsson B, Knutsson A, Lindahl B. Is there an association between shift work and having a metabolic syndrome?: results from a population based study of 27,485 people. Occup Environ Med 2001;58(11):747-52.

13. Åkerstedt T. Work hours and sleepiness. Neurophysiol Clin 1995;25(6):367-75.

14. Jansen NWH, Kant IJ, Van Amelsvoort LGPM, Nijhuis FJN, Van den Brandt PA. Need for recovery from work: evaluating short-term effects of working hours, patterns and schedules. Ergonomics 2003;46(7):664-80.

15. Åkerstedt T, Fredlund P, Gillberg M, Jansson B. Work load and work hours in relation to disturbed sleep and fatigue in a large representative sample. J Psychosom Res 2002; 53(1):585-8.

16. Barton J, Folkard S. Advancing versus delaying shift systems. Ergonomics 1993;36(1-3):59-64.

17. Härmä M. New work times are here-are we ready? [editorial]. Scand J Work Environ Health 1998;24 Suppl 3:3-6.

18. Jansen NWH, Van Amelsvoort LGPM, Kristensen TS, Van den Brandt PA, Kant IJ. Work schedules and fatigue: a prospective cohort study. Occup Environ Med 2003;60 Suppl $1:$ i47-53.

19. Åhsberg E, Kecklund G, Akerstedt J, Gamberale F. Shiftwork and different dimensions of fatigue. Int J Ind Ergon 2000;26:457-65.

20. Koller M, Kundi M, Cervinka R. Field studies of shift work at an Austrian oil refinery. I: health and psychosocial wellbeing of workers who drop out of shiftwork. Ergonomics 1978;21:835-47.

21. Czeisler CA, Moor-Ede MC, Coleman RM. Rotating shift work schedules that disrupt sleep are improved by applying circadian principles. Science 1982;217:460-3.

22. Knauth P. Designing better shift systems. Appl Ergon 1996;27:39-44.

23. Knauth P, Hornberger S. Changes from weekly backward to quicker forward rotating shift systems in the steel industry. Int J Ind Ergon 1998;21(3-4):267-73.
24. Knauth P. The design of shift systems. Ergonomics 1993;36(1-3):15-28

25. Van Amelsvoort LGPM, Schouten EG, Maan AC, Swenne CA, Kok FJ. 24-Hour heart rate variability in shift workers: impact of shift schedule. J Occup Health 2001;43:32-8.

26. Orth-Gomér K. Intervention on coronary risk factors by adapting a shift work schedule to biologic rhythmicity. Psychosom Med 1983;45:405-15.

27. Knauth P, Kiesswetter E. A change from weekly to quicker shift rotations: a field study of discontinuous three-shift workers. Ergonomics 1987;30(9):1311-21.

28. Rosa RR. Examining work schedules for fatigue: it's not just hours of work. In: Hancock PA, Desmond PA, editors. Stress, workload and fatigue. Mahwah (USA): Lawrence Erlbaum Associates; 2001:513-28.

29. Swaen GMH, Van Amelsvoort LGPM, Bültmann U, Kant IJ. Fatigue as a risk factor for being injured in an occupational accident: results from the Maastricht Cohort Study. Occup Environ Med 2003;60 Suppl 1:i88-92.

30. Van Amelsvoort LGPM, Kant IJ, Beurskens AJHM, Schröer CAP, Swaen GMH. Fatigue as a predictor of work disability. Occup Environ Med 2002;59:712-3.

31. Tucker P, Smith L, Macdonald I, Folkard S. Effects of direction of rotation in continuous and discontinuous 8 hour shift systems. Occup Environ Med 2000;57(10):678-84.

32. Barton J, Folkard S, Smith L, Poole CJM. Effects on health of a change from a delaying to an advancing shift system. Occup Environ Med 1994;51:749-55.

33. Walker J. Social problems of shiftwork. In: Folkard S, Monk TH, editors. Hours of work: temporal factors in work-scheduling. New York (NY): John Wiley \& Sons; 1985:211-25.

34. Loudoun RJ, Bohle PL. Work/non-work conflict and health in shiftwork: relationships with family status and social support. Int J Occup Environ Health 1997;3 Suppl 2:S71-7.

35. Jansen NWH, Kant IJ, Kristensen TS, Nijhuis FJN. Antecedents and consequences of work-family conflict: a perspective cohort study. J Occup Environ Med 2003;45(5):479-91.

36. Grandey AA, Cropanzano R. The Conservation of resources model applied to work-family conflict and strain. J Vocat Behav 1999;54(2):350-70.

37. Kant IJ, Beurskens AJHM, Schroër CAP, Nijhuis FJN, Van Schayk CP, Van den Elzen HJ, et al. De Maastrichtse cohort studie naar langdurige psychische vermoeidheid in de arbeidssituatie [The Maastricht cohort study on prolonged mental fatigue and work]. Tijdschr Bedr Verzekeringsgeneeskunde 2000;8:226-32.

38. Kant IJ, Bültmann U, Schröer CAP, Beurskens AJHM, Van Amelsvoort LGPM, Swaen GMH. An epidemiological approach to study fatigue in the working population: the Maastricht Cohort Study. Occup Environ Med 2003;60 Suppl 1:i32-9.

39. Van Veldhoven M, Meijman T. Het meten van psychosociale arbeidsbelasting [Questionnaire on psychological job demands and job stress]. Amsterdam: NIA-TNO; 1994.

40. Sluiter JK, Van der Beek AJ, Frings Dresen MH. The influence of work characteristics on the need for recovery and experienced health: a study on coach drivers. Ergonomics 1999;42(4):573-83.

41. Jansen NWH, Kant IJ, Van den Brandt PA. Need for recovery in the working population: description and associations with fatigue and psychological distress. Int J Behav Med 2002;9(4):322-40.

42. Vercoulen JH, Swanink CM, Fennis JF, Galama JM, van der Meer JW, Bleijenberg G. Dimensional assessment of chronic 
fatigue syndrome. J Psychosom Res 1994;38(5):383-92.

43. Bültmann U, De Vries M, Beurskens AJHM, Bleijenberg G, Vercoulen JHMM, Kant, IJ. Measurement of prolonged fatigue in the working population: determination of a cut off point for the checklist individual strength. J Occup Health Psychol 2000;5(4):411-6.

44. Aaronson NK, Muller M, Cohen PD, Essink Bot ML, Fekkes M, Sanderman R, et al. Translation, validation, and norming of the Dutch language version of the SF-36 Health Survey in community and chronic disease populations. J Clin Epidemiol 1998;51(11):1055-68.

45. Karasek RA. Job content questionnaire and user's guide. Los Angeles (CA): Department of Industrial and Systems Engineering, University of Southern California; 1985.
46. Houtman I. Reliability and validity of the Dutch version of the Karasek Job content questionnaire. In: APA/NIOSH conference on work, stress and health; 1995. Washington (DC): American Psychological Association; 1995.

47. Gründemann RWM, Smulders PWG, De Winter CR. Handleiding Vragenlijst Arbeid en Gezondheid [Manual, questionnaire on work and health]. Lisse: Swets \& Zeitlinger; 1993.

48. SAS Institute. SAS/STAT user's guide, volume 1, version 6 . Cary (NC): SAS Institute Inc; 1989.

49. Kristensen TS. Workplace intervention studies. Occup Med 2000;15(1):293-305.

Received for publication: 27 January 2003 